Student Support, Confidence, Workload, and Video Resources in a New Civil Engineering Graphics Course

Mr. Bradley James Schmid, University of Saskatchewan

Brad Schmid is an assistant professor in Civil, Geological, and Environmental Engineering at the University of Saskatchewan. 


\title{
Student Support, Confidence, Workload, and Video Resources in a New Civil Engineering Graphics Course
}

\begin{abstract}
Through the development of a new course focused on spatial analysis and civil engineering drawings and design, several systems were used for learning management, student response, and video content to improve the educational experience of students and provided feedback to the instructor regarding the performance of the course. The features primarily used in the course were the BlackBoard Learning Management System (LMS), TopHat audience response system, Panopto video platform, and LinkedIn Learning resources.

These tools proved a means of moving from traditional paper-based assignments to electronically submitted drawings and assignments. Lab demonstrations were carried out live but also recorded and provided for future review. A weekly status survey was completed that provided an indication of student workload in the course, the usefulness of video resources, and student confidence in the subject matter.
\end{abstract}

Assignments were customized such that students received individualized questions that were mostly automatically graded. A drawing comparison tool was used to provide graphical feedback on submitted design drawings. A discussion forum was introduced to provide both peer to peer support and instructor support for the computer lab component of the course.

The application of these learning technologies provided many benefits both to the students and instructor of the course. For example, students often benefitted from just-in-time assistance on labs while the instructor benefitted from discovering which aspects of the course students were having difficulty with and which aspects of the course contributed significantly to the workload.

\section{Background, Course Development, and Need for Supports}

A new course in spatial analysis and engineering drawings for civil and geological engineering students has recently been introduced. Prior to 1998, all first-year engineering students were required to complete a single semester course in graphics and descriptive geometry that taught traditional drafting using pencil and paper in a formal classroom with drafting tables. This course was part of a common first year program at that all engineering students follow prior to entering their chosen department for their second year of studies.

After 1998, the first-year program was redesigned to include the basics of drawing and sketching but did not cover drafting to the extent previously covered and required individual Programs (eg. Civil, Mechanical, Chemical, Electrical Engineering) to determine for their individual programs any further Engineering Graphics requirements.

Within the Civil, Geological, and Environmental programs, the decision was taken to require students to complete an introductory AutoCAD course[1] at a neighboring technical institution as part of their program. This was a reasonable measure for the interim but for the longer term, a more integrated offering was desired. A replacement course has now been developed and was first offered in September 2016. 
The current one-semester course consists of 1.5 hours per week of lecture and 3 hours per week for labs. The lecture class size is approximately 100 students and the labs are restricted to a size of 45 students; typically requiring three sections. Teaching assistants are available in the labs to answer students questions related to the use of the software; AutoCAD or Civil 3D.[2]

Laboratory assignments were assigned as either projects or lab experiences depending on the required effort expected from students. Labs consisted of drawings to complete where the CAD software features were demonstrated and video recorded in the lab session. The students would typically have one week, with three hours of lab time in two 1.5-hour sessions, to complete their drawings. The projects would also have a laboratory demonstration (and recording) but the assignments were longer in duration and more laboratory sessions (typically four 1.5-hour labs) were available for the students to complete their drawings.

The first iteration of the course presented many challenges which are discussed in a companion paper.[3] These challenges resulted in the instructor pursuing several methods for improving the delivery of the course and student satisfaction in the course. This paper focusses on the use of technology in the course, student satisfaction, and the benefits to both students and instructors. The principal problems identified in the first offering of the course included some disconnect between lecture content and lab content, frustration with the use of software, and the workload for the course.

The technology used in the course includes the learning management system BlackBoard [4], the audience response system TopHat [5], the video recording platform Panopto [6], video tutorials from Lynda.com [7], and the use of Webex [8] video conferencing during computer laboratories. These technologies were all available to students at our University at no extra charge because the University had procured campus wide licenses from each provider. These technologies are managed on Campus by the University's Information Technology department, which improves the coordinated use in a course such as this.

As no comparison between similar technology providers was undertaken, this paper does not draw any conclusions on the efficacy of one technology provider relative to their competition.

\section{Learning Management System}

Blackboard was used as the course learning management system (LMS) and served the principal purpose of providing a central site for the distribution of notes, posting of assignments, submission of assignments, distribution of email announcements, reporting of student grades, and to administer the course discussion forum. Most, if not all, of these functions can be met with most any commercial learning management system.

The discussion forum introduced through BlackBoard was a valuable addition to the course and provided many benefits to both the students and instructor. The discussion forum was introduced as an additional method that students could use to get assistance in the course from either their peers, the teaching assistants, or the instructor. Participation marks (up to 3\% of the student's final grade) were offered as an incentive for students to participate in peer-to-peer learning through the forum. 
When a student posted a question to the discussion forum, it was visible to anyone in the class and most students had email notifications set such that they would receive notification when a new post was made to the forum. The teachings assistants and instructor typically waited a day prior to answering posts on the forum to allow students the opportunity to answer these questions. While questions to the teaching assistants and instructor remained plentiful in-person during the lab periods, almost no questions were received from students outside of the lab period except through the discussion forum.

In addition to drastically reducing the number of office visits and emails the course instructor received, the forum also helped to identify common errors or issues that students were experiencing and allowed for the creation of simple one-page instructions (we termed tip sheets) that would help resolve common issues and were posted to the course BlackBoard site.

\section{Student Surveys}

Student surveys were conducted at the beginning of the lecture period that followed the completion of the Lab assignments. These surveys were conducted using the audience response system TopHat. The main purpose of the survey was to acquire feedback on the course workload, difficulties students were having in the Labs, and student confidence with the CAD software activities. The students were asked to indicate if they had experience using CAD software prior to the course. One-third of the students who responded ( 21 of 63 survey responses) had CAD experience prior to the course. In each of the TopHat surveys, the students were asked the following questions:

1. How long did the last Lab assignment take you to complete?

2. What was the most difficult aspect of the lab?

3. How confident are you that you could complete a similar assignment for an employer?

Question 3 above was modified for each of the labs to specifically ask about the main deliverable of the preceding lab assignment. For example, following a lab that had the students using grading tools to draw stockpiles and retention ponds in Civil3D, students were asked:

"If you were asked by an employer to create a basic structure (pond or stockpile) using grading objects and calculate the volume of earth that would have to be moved, how confident are you that you could do that?"

Questions 1 and 3 are reviewed in class with the students so that they can see how they compare to their peers and it allows routine encouragement for those who may take longer to complete an assignment to seek out additional supports or help in the lab sessions. Question 2 is not easily reviewed in class using the audience response system but does provide valuable information on which topics may require additional resources (such as the tip sheets previously mentioned) or which aspects of the course require improvements in either lecture content or lab demonstration.

Figure 1 shows the student survey results for the workload associated with 8 lab assignments contrasting the time to complete each lab assignment for those who had prior CAD experience and those who did not. 


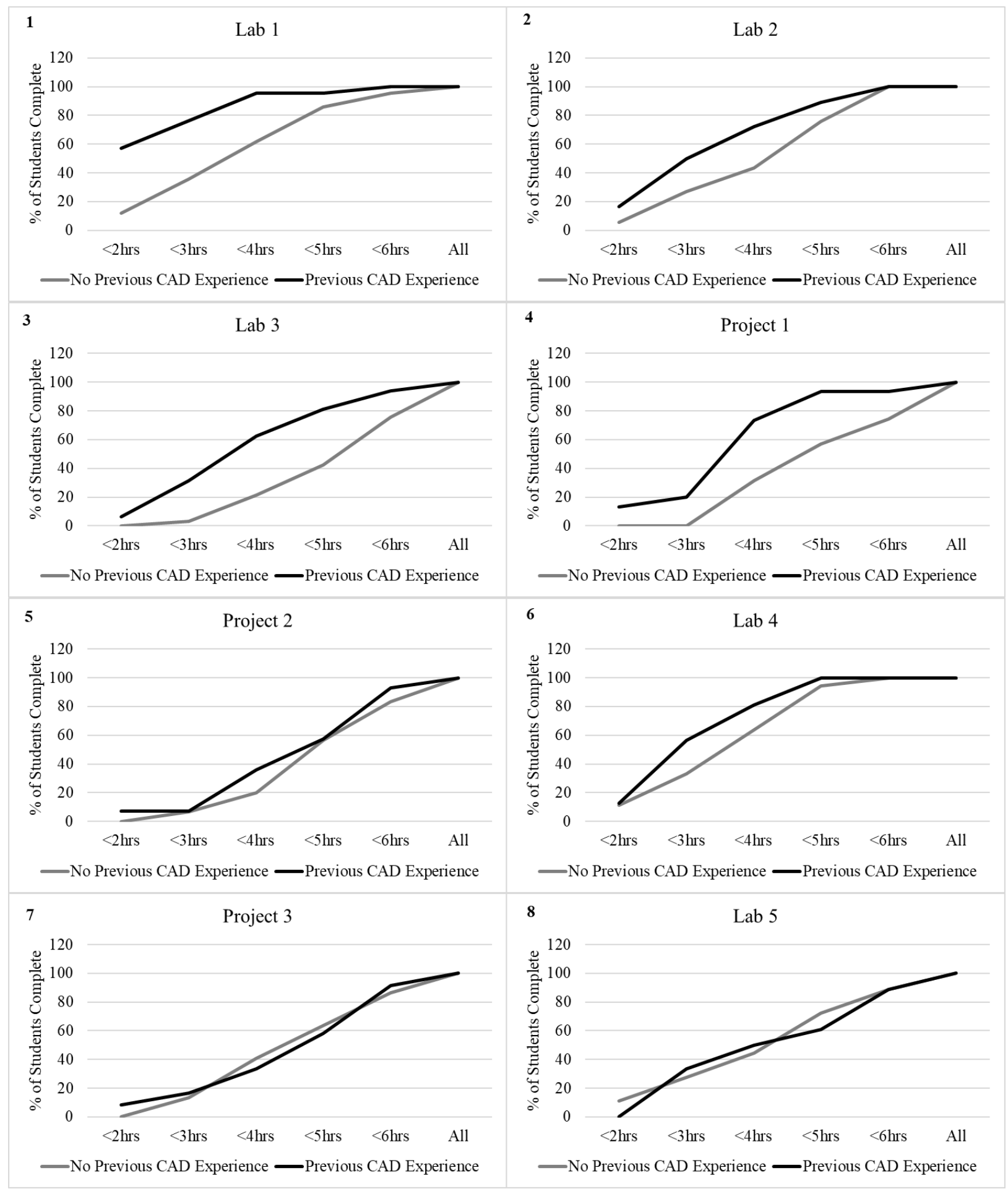

Figure 1 Student reported workload for 8 lab-based assignments. Graphs indicate the cumulative percentage of surveyed students who completed their assignment in the time given on the X-axis. The number in the top left corner indicates the chronological order of lab assignments.

The results show that for the first four lab assignments, there is a noticeable difference in the amount of time it takes students with no previous CAD experience to complete the labs 
compared to those who do have previous experience with CAD. This difference substantially decreases for lab assignments 5 and 6 (Project 2 and Lab 4) and shows no discernable difference in the time to complete lab assignments 7 and 8 (Project 3 and Lab 5). This is a positive result as it indicates that the students without prior CAD experience "catch up" to their peers with prior CAD experience near the midpoint of the course.

Figure 2 below shows student confidence by lab assignment for students with no prior CAD experience and for students with prior CAD experience. From the figures, it is evident that students with prior CAD experience exhibit higher levels of confidence than those with no prior CAD experience. It should be noted that the main trade-off between the two groups of students is that those with prior experience more frequently indicate being very confident while those with no prior experience more commonly indicate being somewhat confident; both groups have similar rates for the not confident response. The data presented here is consistent with the study by Metraglia et.al. [9] who found that first-year engineering students from technical high schools that most likely had CAD offered exhibited higher levels of self-efficacy compared to their peers who did not have prior CAD experience.

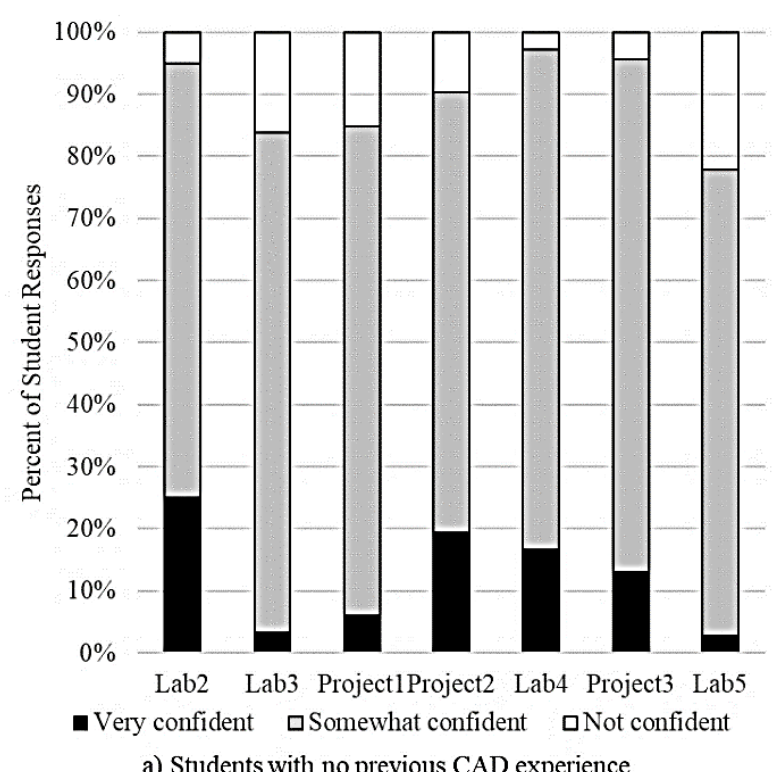

a) Students with no previous $\mathrm{CAD}$ experience

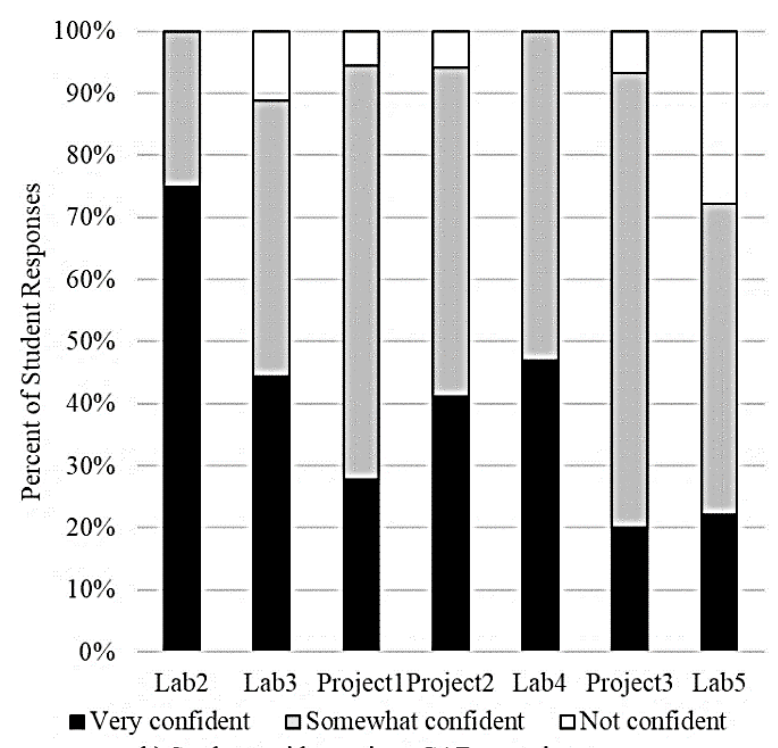

b) Students with previous $\mathrm{CAD}$ experience

Figure 2 Student confidence following lab assignments for (a) students with no previous CAD experience compared to (b) students with previous CAD experience. Note: The student confidence data for Lab1 was not available due to a technological error.

\section{Recorded Demonstrations}

In each of the lab sessions, the demonstration is recorded in real time and consists of the CAD software screen and voice instruction from the course instructor. These recordings are not processed in any way and are simply made available to the students through the course LMS. Students do have the ability to advance the video, rewind the video, play the video back at increased speed (eg. 1.5x the original speed), and other common playback options. These lab demonstrations are recorded each year in the course and typically not reused in subsequent course offerings, though they could be reused. 
As can be seen from Figure 3 below, the first 2 lab recordings were not used by many of the students with prior CAD software experience but, particularly for Lab 2 there was considerable (>50\%) use by students who did not have experience using CAD software. The usage of the videos increases to approximately $90 \%$ or greater by the $4^{\text {th }}$ of 8 lab assignments.

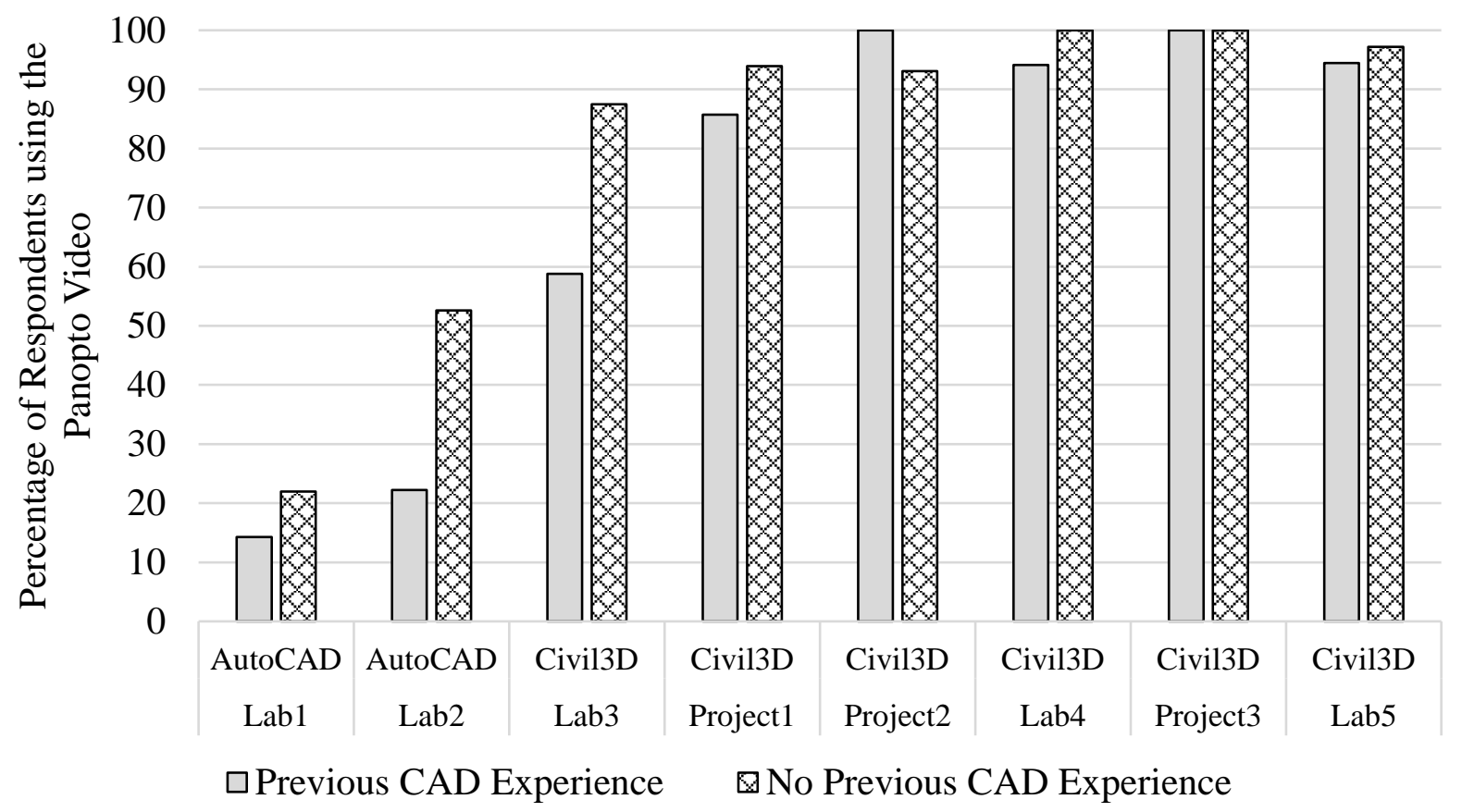

Figure 3 Percentage of Student Respondents who used the Lab Demonstration Videos separated by those who had CAD experience prior to the course and those who did not. Also indicated is the software used in the Lab; basic AutoCAD or Civil3D.

\section{Online Video Resources}

Linked Learning, formerly Lynda.com, videos are available for student use to help learn the software. The instructor made a list of relevant videos available for each Lab to the students. These videos provided an additional instructional resource for students who may desire additional resources. These Lynda.com videos are of much superior quality and provide a larger breadth of coverage than the recorded demonstration videos.

These video resources are extensive; consisting of example files and over three hours of video for AutoCAD and over 9 hours of video for Civil3D though only a subset of these videos was included in the playlists defined by the course instructor.

It was found that some students did make use of and appreciated the LinkedIn videos. Most of the students did not routinely use these videos, preferring to re-watch the lab demonstration video. Even though the lab demonstration video was of poorer production quality, it appears that most students preferred this video resource because it was considered to be a 'custom' video specific to the purpose of the lab assignment. 


\section{Use of video conferencing during lab demonstrations}

The lab demonstrations are conducted in a computer lab with spaces for 45 students. Each student has a Windows based personal computer with dual screens. AutoCAD and Civil 3D are software that are primarily used on a single screen with the option for tool bars and other windows to be shown on the secondary monitor if desired. The computer available to the instructor only has a single computer screen and the projector displays a duplicate view of that monitor.

During the lab demonstrations, it was observed that for students to follow along they had to work on their screens and then look up to see what was being accomplished on the projector screen during the demonstration. This act of switching between their own screen and the projector screen causes students to lose track or fall behind during this demonstration. This happens because of the physical eye movement required and because many of the icons in the software are too small to see from a distance and cannot be made large enough for presentation in this setting.

A simple adaptation of the Webex video conferencing service was used to help alleviate the demonstration restrictions. The instructor created a meeting room for the lab sessions and shared their screen allowing each student to open a web browser with the demonstration image on their second monitor. This allows the students to simply listen to the instructions from instructor while using one monitor for their CAD work and the other to more easily see the demonstration. This shared screen setup is displayed in Figure 4.

The result of this implementation was that the instructor was not interrupted as frequently to repeat part of the demonstration, fewer students fell behind during the demonstration, and the instructor was able to proceed faster through the demonstration activity, which in turn allowed students more working time in the lab.

\section{Results from Student Surveys}

The results from the student survey were presented in Figures 1, 2, and 3 showing the course workload, student confidence, and the use of course resources were extremely valuable to the instructor in the adaptation of the course to improve student performance and student satisfaction with the course.

Metraglia et.al. [9] found that self-efficacy beliefs and performance were positively correlated for students with prior CAD experience but there was no correlation between self-efficacy and performance among students without prior CAD experience. This same correlation between selfefficacy beliefs and previous CAD experience was demonstrated through the survey in this course and indicated that there is an advantage, at least in terms of confidence, in having previous subject experience. 


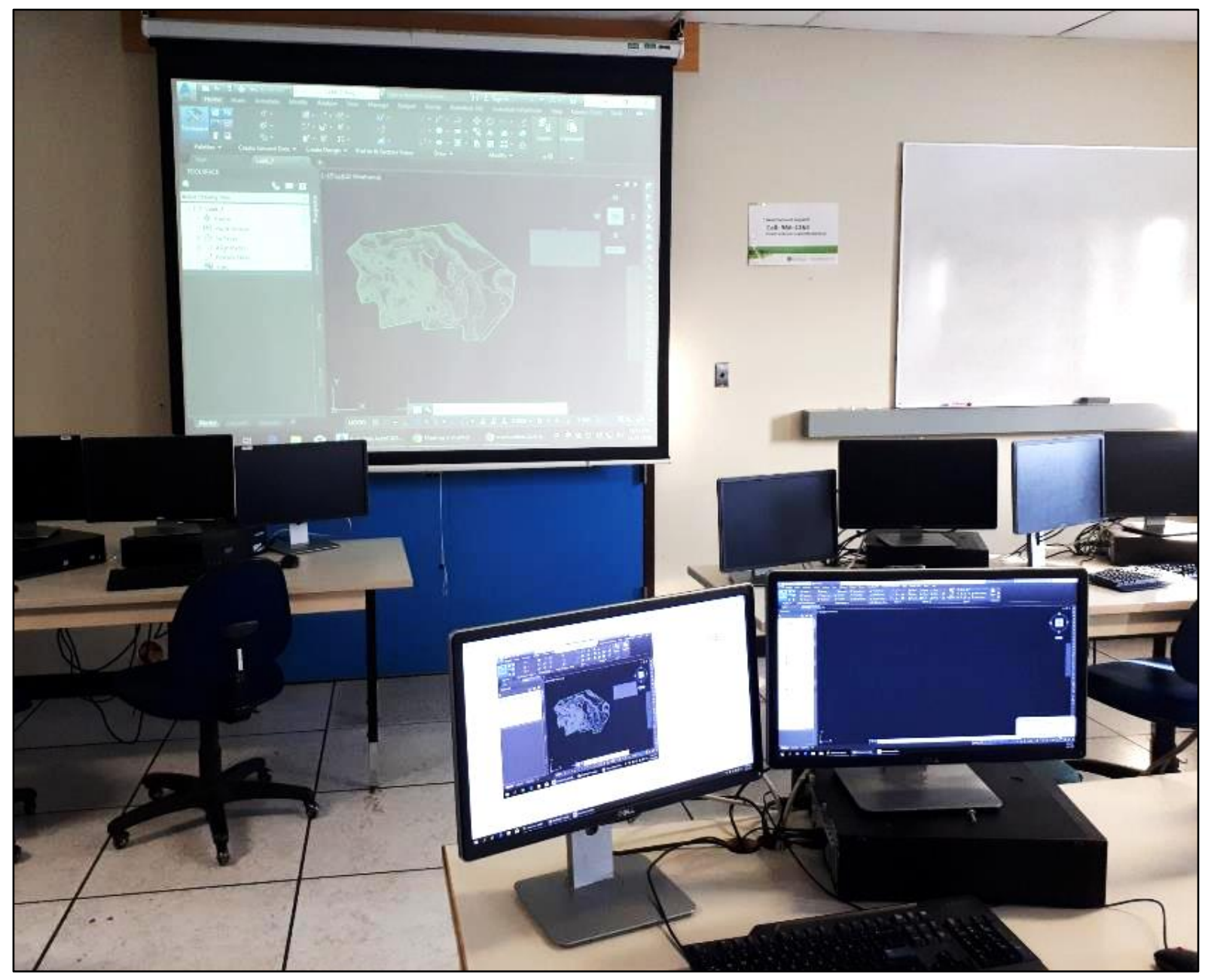

Figure 4 Typical Student workstation showing the personal computer with dual monitors. the left monitor showing the shared demonstration through Webex and the right monitor showing the student's workspace.

\section{Benefits to Students and Instructors}

The benefits to students through the use of technology in this course was the abundance of options to receive additional support while learning the CAD software. These benefits included multiple options for video resources and an online discussion forum that typically provided fast responses to questions. The surveys helped students understand their workload relative to others in the class, which may lead underperforming students to ask for additional help in the course. The discussion forum often provided solutions to student problems faster than emailed questions. This was especially true during the evening when the instructor is typically unavailable but peers maybe working on the same labs and be able to provide responses.

The benefits to the instructor are numerous and include being able to adapt to student workload, student confidence, a reduction in the number of office visits and email inquiries, and the ability to observe common issues that students are having in the course that may otherwise not be noticed. Having a lab demonstration video library from previous years has also been beneficial in 
the training of teaching assistants for the course and in the event of instructor illness or unexpected unavailability for a lab demonstration.

The instructor was also able to see the difference in workload and self-efficacy between students with prior $\mathrm{CAD}$ experience and those who were using $\mathrm{CAD}$ for the first time in this course.

\section{Conclusion}

This paper demonstrates a coordinate use of available technological supports to a second-year spatial analysis and engineering drawings course to improve the student experience and coordination of the course.

\section{References}

[1] “AutoCAD For Mac \& Windows | CAD Software | Autodesk." [Online]. Available: https://www.autodesk.ca/en/products/autocad/overview. [Accessed: 02-Feb-2020].

[2] “Civil 3D | Civil Engineering Software | Autodesk." [Online]. Available: https://www.autodesk.ca/en/products/civil-3d/overview. [Accessed: 02-Feb-2020]. , "Challenges of Developing a New Engineering Drawings Course for Civil Engineers," in ASEE Annual Conference and Exposition, Conference Proceedings, 2020.

[4] "North America| Blackboard.com." [Online]. Available: https:/www.blackboard.com/. [Accessed: 02-Feb-2020].

[5] "TopHat: Education Software For Professors \& Educators." [Online]. Available: https://tophat.com/. [Accessed: 02-Feb-2020].

[6] "Panopto Video Platform For Business \& Education." [Online]. Available: https://www.panopto.com/. [Accessed: 02-Feb-2020].

[7] "Lynda: Online Courses, Classes, Training, Tutorials." [Online]. Available: https://www.lynda.com/. [Accessed: 02-Feb-2020].

[8] "Video Conferencing, Online Meetings, Screen Share | Cisco Webex." [Online]. Available: https://www.webex.com/. [Accessed: 02-Feb-2020].

[9] R. Metraglia, V. Villa, G. Baronio, and R. Adamini, "High school graphics experience influencing the self-efficacy of first-year engineering students in an introductory engineering graphics course," Eng. Des. Graph. J., vol. 79, no. 3, pp. 16-30, 2015. 